SECTION 31. Economic research, finance, innovation, risk management.

\author{
Almaz Shairbekovich Atirbekov \\ teacher \\ Kazakh University of Technology and Business, Kazakhstan \\ my_docs@inbox.ru
}

\title{
INVESTMENT MANAGEMENT SYSTEM IN THE REPUBLIC OF KAZAKHSTAN
}

Abstract: This article describes the problems of management of investment processes in the Republic of Kazakhstan. Identified and the necessity of enhancing the competitiveness of the country's economy in the long term by attracting and implementing investment projects.

Key words: investment, diversification, competitiveness, industrial and innovative development, post-industrial economy, modernization, infrastructure.

\section{СИСТЕМА УПРАВЛЕНИЯ ИНВЕСТИЦИОННЫМИ ПРОЦЕССАМИ В РЕСПУБЛИКЕ КАЗАХСТАН}

Аннотация: В данной статье рассмотрены проблемы системы управления инвестиционными процессами в Республике Казахстан. Выявлена и обоснована необходимость повымения конкурентоспособности экономики страны в долгосрочном периоде за счет привлечения и реализации инвестиционных проектов.

Ключевые слова: инвестиции, диверсификация, конкурентоспособность, индустриально-инновационное развитие, постиндустриальная экономика, модернизация, инфраструктура.

В целях обеспечения диверсификации и повышения конкурентоспособности экономики Республики Казахстан в долгосрочном периоде была утверждена Государственная программа по форсированному индустриально-инновационному развитию Республики Казахстан на 2010-2014 годы (далее - Программа).

Целью Программы является обеспечение устойчивого и сбалансированного роста экономики через диверсификацию и повышение ее конкурентоспособности. Где одной из главных задач является усиление социальной эффективности развития приоритетных секторов экономики и реализации инвестиционных проектов.

На период до 2015 года основным приоритетом политики форсированной индустриализации является реализация крупных инвестиционных проектов в традиционных экспортоориентированных секторах экономики, с мультипликацией новых бизнес возможностей для малого и среднего бизнеса через целенаправленное развитие казахстанского содержания, последующих переделов и переработки.

Инициаторами продвижения крупных проектов стали АО Фонд Национального Благосостояния «Самрук-Казына», системообразующие компании топливно-энергетического и металлургического секторов экономики, а также стратегические иностранные инвесторы.

Параллельно осуществляется формирование и/или усиление отраслей экономики, не связанных с сырьевым сектором и ориентированных на внутренний, а в последующем на региональные рынки (страны Таможенного Союза, Центральной Азии).

Государству необходимо поддерживать инициативы казахстанского среднего и малого бизнеса, направленные на трансферт передовых технологий, привлечение 
иностранных инвесторов для создания современных импортозамещающих производств, с перспективой развития их экспортной ориентированности.

В целях формирования основ постиндустриальной экономики важно продолжить развитие национальной инновационной инфраструктуры и поддержку научно-технологических заделов, имеющих перспективы коммерциализации.

В целом, государственная поддержка диверсификации экономики должна осуществляться через реализацию системных мер экономической политики на макро и секторальном уровнях, а также селективных мер поддержки конкретных секторов экономики и проектов.

Системные меры экономической политики должны концентрироваться на формировании благоприятной макросреды и инвестиционного климата, мерах по повышению производительности и конкурентоспособности национальной экономики.

Селективные меры необходимо осуществлять на основе комбинированного пакета мер финансовой и нефинансовой поддержки приоритетных секторов и проектов.

Государство должно системно выстроит свое взаимодействие с бизнесом на основе формирования эффективных институтов сотрудничества, как на республиканском, так и региональном уровнях.

Адекватная объективному состоянию экономики траектория политики индустриализации до 2015 года должна иметь внутреннюю согласованность с ресурсными, инфраструктурными, институциональными и технологическими ограничениями.

Системный характер встроенных в Программу механизмов, стимулирующих диверсификацию и технологическую модернизацию экономики, обеспечит:

- создание благоприятных макроэкономических условий;

- улучшение бизнес-климата и стимулирование притока инвестиций;

- массовую технологическую модернизацию и развитие национальной инновационной системы;

- повышение качества человеческого капитала. [2]

Концентрация ресурсов государства и бизнеса на развитии приоритетных секторов экономики должна сопровождаться интерактивным процессом согласования решений государства и бизнеса, использованием современных информационных систем мониторинга и конкретных инструментов реализации.

Информационная система управления инвестиционными процессами в Республике Казахстан - это инструмент анализа и мониторинга инвестиционных проектов, реализуемых в рамках Государственной программы по форсированному индустриально-инновационному развитию Казахстана на 2010-2014 годы.

Система ориентирована на обеспечение:

- мониторинга и продвижения частных и бюджетных инвестиционных проектов Правительства и Акимов регионов;

- конструктивного диалога между государством и частным сектором для реализации проектов;

- привлечения «якорных» (стратегических) инвесторов, в том числе иностранных, для производства несырьевой высокотехнологичной продукции, с акцентом на освоение рынков Таможенного Союза;

- информированности иностранных и отечественных компаний о перспективных, для вложения инвестиций, проектам, и открывающимся бизнес возможностям по вводимым проектам. [2]

Система позволяет вести мониторинг и обработку информации по проектам для расчета показателей в разрезе отраслей регионов, расчет валовой добавленной стоимости (ВДС), а также позволяет оценить социально-экономический эффект от реализации инвестиционных проектов на макро и микро уровнях. 
Система состоит из следующих компонентов:

1.Сводная Карта индустриализации (Республиканская и региональная Карта индустриализации) - содержит сводную информацию об инвестиционных проектах.

2. Дорожная карта бизнеса - 2020 - содержит сводную информацию о проектах данной Программы.

3. Республиканские, Региональные бюджетные инвестиции.

4. Бизнес идеи - содержит информацию о перспективных инвестиционных проектах.

5. Схема рационального размещения производственных мощностей - состоит из 6 подблоков: «Главная страница», «Энергетическая инфраструктура», «Транспортная инфраструктура», «Водные ресурсы», «Трудовые ресурсы», «Минерально-сырьевые ресурсы».

6. Личные кабинеты - для руководителей.

7. Бизнес-сообщество - блок предназначен для публичного доступа к информационно - аналитической системе управления проектами.

8. Проектный офис - блок предназначен для публичного доступа к информационно - аналитической системе управления проектами. [3]

В рамках инвестиционной политики необходимо совершенствовать законодательную базу, определяющую правовые и экономические основы стимулирования инвестиций.

Несмотря на определенные результаты, политика диверсификации и инновационного развития не была реализована в полной мере в связи с наличием ряда системных эффектов, объективно присущих ресурсным экономикам стран с развивающимися рынками:

- проявляются симптомы "голландской болезни" экономики, способствуя воспроизводству эффекта перераспределения ресурсов (инвестиционных, трудовых) в сырьевой сектор;

- рыночный механизм в этот период оказался не в состоянии подавать сигналы, предотвращающие «перегрев» отдельных секторов экономики, и не смог помочь государству выстроить «правильную» структуру экономики;

- политика диверсификации столкнулась с отсутствием необходимой критической массы для ее продвижения.

Масштабы выделенных государственных инвестиций на диверсификацию были недостаточны и распылены, что не могло привести к каким-либо серьезным структурным сдвигам.

В результате структура экономики сохранила сырьевую направленность, а структура занятости характеризует низкую эффективность использования трудового потенциала.

Среди факторов негативно влияющих на привлекательность многих перспективных для Казахстана секторов экономики ключевыми являются следующие:

- низкая емкость внутреннего рынка;

- отдаленность от крупных рынков сбыта и отсутствие удобной логистики влекут значительные расходы на транспортировку товаров;

- относительно высокая стоимость рабочей силы при нехватке высококвалифицированных кадров и отсутствие соответствующей инфраструктуры;

- отсутствие централизованной системы по работе с инвесторами, в том числе с иностранными, а также недостаточно эффективные меры государственной поддержки инвестиций.

В настоящее время расширение каналов привлечения прямых иностранных инвестиций осуществляется через повышение инвестиционной привлекательности 
специальных экономических зон (СЭ3), индустриальных зон (ИЗ) и развитие механизмов государственно-частного партнерства.

Мировой опыт свидетельствует о том, что создание СЭЗ и ИЗ является фактором ускоренного экономического роста за счет активизации международного товарооборота, мобилизации инвестиций, углубления интеграционных экономических процессов.

Инвестиционная привлекательность казахстанских СЭЗ и ИЗ в настоящее время недостаточно высока, так как условия их функционирования не вполне ориентированы на реальные потребности и интересы инвесторов.

В целом система привлечения инвестиций в Республику выстроена, инвестиционная привлекательность планомерно развивается, но для дальнейшего совершенствования государственной политики в этой области требуется внесение определенных изменений как в законодательное, так и в институциональное поле страны.

Исследование проведено под руководством: доктора экономических наук, профессора Анафияева Жибек Анафияевны, Казахский университет технологии и бизнеса, Казахстан.

\section{References:}

1. Закон Республики Казахстан «Об инвестициях» от 8 января 2003 года № 373-II

2. Указ Президента Республики Казахстан от 6.03.2000 г № 349 «Об утверждении Правил предоставления льгот и преференций при заключении контрактов с инвесторами, осуществляющими инвестиционную деятельность в приоритетных секторах экономики»

3. Приказ Председателя Комитета по инвестициям Министерства индустрии и торговли Республики Казахстан от 18 марта 2003 года № 18-П «О некоторых вопросах государственной поддержки инвестиций»

4. Постановление Правительства Республики Казахстан от 8 мая 2003 года № 436 «О некоторых вопросах реализации Закона Республики Казахстан «Об инвестициях» и др.

5. Государственная программа форсированного индустриально - инновационного развития на 2010 - 2014 г.г.

6. Система управления инвестиционными процессами в Республике Казахстан [Электронный pecypc] URL: www.ip.economy.kz. (дата доступа 5.05.2014)

7. Голодзе И.Н. Финансирование и кредитование инвестиций. Учебное пособие, Павлодар 2012 г.

8. Шарп У., Александер Г., Бэйли Дж. Инвестиции. Учебник, 2001 г.

9. Зубченко Л.А. Иностранные инвестиции: Учебное пособие. М., 2006 г.

10. World Investment Report 2003. FDI Policies for Development: National and International Perspectives/ N.Y.- Geneva, 2003. 